\title{
RANCANG BANGUN APLIKASI INFORMASI NAMA STASIUN KERETA JURUSAN JAKARTA - CIREBON BERBASIS SMARTPHONE ANDROID
}

\author{
Rohadi, Husni Teja Sukmana, Rayi Pradono Iswara \\ ${ }^{1,2,3}$ Program Studi Teknik Informatika, Fakultas Sains dan Teknologi \\ UIN Syarif Hidayatullah Jakarta \\ ${ }^{1}$ rohaditarsum@gmail.com, ${ }^{2}$ husniteja@uinjkt.ac.id, ${ }^{3}$ rayi.iswara@uinjkt.ac.id
}

\begin{abstract}
ABSTRAK
Diantara banyaknya jasa pelayanan masyarakat, adalah kendaraan umum seperti kereta api (KA) dan kereta rel listrik (KRL) yang banyak sekali digunakan sebagai kendaraan alternatif dalam melakukan perjalanan, karena harga perjalanan yang terjangkau juga waktu perjalanan yang relatif stabil karena memiliki jalur khusus, meski keterlambatan waktu kadang terjadi tapi tingkatnya lebih rendah dibanding dengan angkutan umum seperti bus, mikrolet, atau angkot. Sarana yang ditawarkan oleh kereta api (KA) dan kereta rel listrik (KRL) adalah waktu yang stabil dan harga yang terjangkau karena terdapat kelas-kelas untuk jenis KA dan KRL yaitu kelas Ekonomi, Bisnis, Eksekutif. Dikarenakan jalur khusus KA dan KRL ini lebih banyak mengambil jalur yang jauh dari kawasan penduduk (pertimbangan akibat resiko kecelakaan) atau jalan umum yang besar ditambah dengan kecepatan KA atau KRL yang konstan mengakibatkan penumpang sulit mencari informasi tentang daerah atau lokasi yang tengah dilewati dan yang akan dituju. Sehingga penumpang kebingungan dimana harus turun, jika adapun informasi di stasiun tidak memadai dan kurang layak untuk sebuah kenyamanan informasi. Ada beberapa aplikasi yang sudah ada seperti Google Map. Aplikasi tersebut memang dapat melihat lokasi peta secara real time, akan tetapi aplikasi ini tidak dapat memberikan notifikasi menggunakan suara. Disini kami akan menggabungkan notifikasi agar penumpang dapat mengetahui dimana posisi kereta walaupun device dalam keadaan stand by, dengan memanfaatkan teknologi GPS sebagai penentu koordinat dari setiap stasiun singgah yang telah di tentukan.
\end{abstract}

Kata kunci: Transportasi, Kereta Api (KA), Kereta Rel Listrik(KRL), Android, Google Map..

\section{Pendahuluan}

\subsection{Latar Belakang}

Diantara banyaknya jasa pelayanan masyarakat, adalah kendaraan umum seperti kereta api (KA) dan kereta rel listrik (KRL) yang banyak sekali digunakan sebagai kendaraan alternatif dalam melakukan perjalanan, karena harga perjalanan yang terjangkau juga waktu perjalanan yang relatif stabil karena memiliki jalur khusus, meski keterlambatan waktu kadang terjadi tapi tingkatnya lebih rendah dibanding dengan angkutan umum seperti bus, mikrolet,atau angkot.

Sarana yang ditawarkan oleh kereta api (KA) dan kereta rel listrik (KRL) adalah waktu yang stabil dan harga yang terjangkau karena terdapat kelas-kelas untuk jenis KA dan KRL yaitu kelas Ekonomi, Bisnis, Eksekutif.

Berdasarkan hasil survey yang dilakukan penulis dengan mewawancarai lima belas mahasiswa dan warga wialyah tiga Cirebon yang tinggal di Jakarta yang melakukan perjalanan pulang atau pergi menggunakan transportasi kereta api, menyatakan $80 \%$ mengalami kesulitan mengetahui nama stasiun yang tengah disinggahi dan $86,66 \%$ menyatakan perlu adanya aplikasi bantu yang dapat memberikan informasi tentang nama-nama stasiun singgah.
Dari data hasil survey di atas, maka dapat di simpulkan terdapat sebuah permasalahan sebagai berikut.Dikarenakan jalur khusus KA dan KRL ini lebih banyak mengambil jalur yang jauh dari kawasan penduduk (pertimbangan akibat resiko kecelakaan) atau jalan umum yang besar ditambah dengan kecepatan KA atau KRL yang konstan mengakibatkan penumpang sulit mencari informasi tentang daerah atau lokasi yang tengah dilewatidan yang akan dituju. Sehingga penumpang kebingungan dimana harus turun, jika adapun informasi di stasiun tidak memadai dan kurang layak untuk sebuah kenyamanan informasi.

Ada beberapa aplikasi yang sudah ada seperti Google Map. Aplikasi tersebut memang dapat melihat lokasi peta secara real time, akan tetapi aplikasi ini tidak dapat memberikan notifikasi menggunakan suara. Disini kami akan menggabungkan notifikasi agar penumpang dapat mengetahui dimana posisi kereta walaupun device dalam keadaan stand by.

\subsection{Rumusan Masalah}

Berdasarkan latar belakang yang telah diuraikan di atas, maka diambil suatu rumusan masalah yaitu:

1. Apakah teknologi Android dan GPS dapat membantu pengguna kereta menentukan lokasi stasiun yang akan disinggahi? 
2. Bagaimana hasil uji coba teknologi Android pada smartphone untuk menentukan lokasi stasiun singgah?

\subsection{Rumusan Masalah}

Karena terbatasnya waktu dan terbentur oleh biaya penelitian, demi memanfaatkan waktu yang sangat singkat dan hasil yang optimal. Maka penulis membatasi masalah yang akan dibahas adalah:

1. Aplikasi ini hanya berbasis Android.

2. Menggunakan koordinat dari Google map.

3. Aplikasi ini hanya untuk angkutan kereta api.

4. Trayek kereta api jurusan Jakarta - Cirebon.

5. Radius pemberitahuan dapat berjalan dalam jarak 1KM sebelumsampai pada lokasi yang dituju.

6. Minimum spesifikasi perangkat yang digunakan: Jelly Bean 4.1, Dual Core 1 Ghz, Ram 512, Memory Internal $4 \mathrm{~Gb}$

\subsection{Tujuan Penelitian}

Tujuan dari penelitian skripsi yang dilakukan

tersebuat adalah untuk:

1. Merancang suatua aplikasi Android pemberitahuan nama-nama stasiunyang secara otomatis dapat berjalan dalam bentuk suara.

2. Menghasilkan aplikasi pemberitahuan yang dapat bermanfaat bagi masyarakat yang melakukan perjalanan menggunakan transportasi umum Kereta Api.

3. Memberikan pelayanan bagi para penumpang baik yang pertama kali atau yang sudah lamamenggunakan sarana transportasi kereta api

\section{LANDASAN TEORI}

\subsection{Pengertian Transportasi}

Sistem transportasi berkembang sesuai dengan kebutuhan manusia pada masa lalu, ketika mobilitas penduduk masih sangat rendah dan luas mobilitasnya masih terbatas didalam lingkungan hidupnya manusia belum begitu membutuhkan sarana transportasi. Akan tetapi ketika tingkat mobilitas semakin tinggi dan jangkauannya semakin luas maka dibutuhkan sarana transportasi yang memadai dan menunjang mobilitasnya.

Perkembangan transportasi dalam sejarah bergerak dengan sangat perlahan, berevolusi dengan terjadi perubahan sedikit-demi sedikit, yang sebenarnya diawali dengan perjalan jarak jauh berjalan kaki pada jaman paleolithic. Sejarah manusia menunjukkan bahwa selain berjalan kaki juga dibantu dengan pemanfaatan hewan yang menyeret suatu muatan yang tidak bisa diangkat oleh manusia dan penggunaan rakit di sungai. Beberapa rekaman mengenai transportasi terekam dalam relief yang dipahat dibatu pada daerah Mesir Kuno dan daerah sekitarnya yang terekam dalam Relief yang ditemukan di Ibukota Assyrian Dur Sharrukin, 8 abad SM.

\subsection{Smartphone}

Smartphone atau telepon pintar dalam terjemahan bahasa Indonesia merupakan komputasi bergerak (mobile) dalam konvergensi antara komunikasi, computer, dan pengguna perangkat elektronik yang menjadi terminal bergerak terpadu dengan membawa fungsi mobilitas dan akses jaringan di semua tempat.

Menurut Pei Zheng dan Lionel Ni mendefinisikan smartphone sebagai sebuah kelas baru pada teknologi telepon seluler yang mampu memfasilitasi akses data dan pemrosesan informasi dengan kemampuan komputasi secara signifikan. Selain memiliki fungsi tradisional yang terdapat pada telepon seluler seperti menelpon dan berkirim pesan (short messages Services), smartphone dilengkapi dengan manajemen informasi personal (PIM) dan komunikasi ke beberapa media akses nirkabel.

\subsection{Android}

Android adalah sebuah platform pertama yang betul-betul terbuka dan komprehensif untuk perangkat mobile, semua perangkat lunak yang ada difungsikan untuk menjalankan sebuah mobile device tanpa memikirkan kendala kepemilikan yang menghambat inovasi pada teknologi mobile (Meier, 2008). Dalam definisi lain, android merupakan subset perangkat lunak untuk perangkat mobile berbasis linux yang meliputi sistem operasi, middleware, dan aplikasi inti yang dirilis oleh Google (Nazaruddin, 2010). Sedangkan Android SDK (Software Development Kit) menyediakan Tools dan API yang diperlukan untuk mengembangkan aplikasi pada platform Android dengan menggunakan bahasa pemrograman Java.

\subsection{Global Positioning System (GPS)}

Global Positioning System adalah sistem untuk menentukan letak di permukaan bumi dengan bantuan penyelarasan (synchronization) sinyal satelit. Sistem ini menggunakan 24 satelit yang mengirimkan sinyal gelombang mikro ke Bumi. Sinyal ini diterima oleh alat penerima di permukaan, dan digunakan untuk menentukan letak, kecepatan, arah, dan waktu.

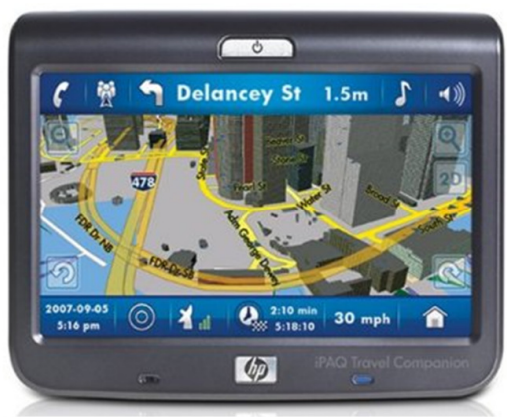

Gambar 1 Global Positioning System (GPS) 


\section{Metodologi Penelitian}

Metode Pengumpulan Data yang peneliti gunakan adalah wawancara, kuesioner, studi pustaka, dan studi sejenis. Sedangkan metode pengembangan sistem yang peneliti gunakan dalam penelitian ini adalah Rapid Application Development (RAD), yang memiliki tahapan-tahapan berikut (Kendall, 2010) : Fase Perencanaan Syarat-syarat, Fase Workshop Design, Fase Implementasi.

\subsection{Fase perencanaan Syarat-syarat}

Dalam fase ini, pengguna dan penganalisis bertemu untuk mengidentifikasikan tujuan-tujuan aplikasi atau sistem serta untuk mengidentifikasi syarat-syarat informasi yang ditimbulkan dari tujuantujuan tersebut. Fase ini memerlukan peran aktif mendalam dari kedua kelompok tersebut. Selain itu juga melibatkan pengguna dari beberapa level yang berbeda dalam organisasi. Orientasi dalam fase ini ialah menyelesaikan masalah-masalah perusahaan. Meskipun teknologi informasi dan sistem bisa mengarahkan sebagian dari sistem yang diajukan, fokusnya akan selalu tetap pada upaya pencapaian tujuan-tujuan perusahaan.

\subsection{Fase Workshop Design}

Fase ini adalah fase untuk merancang dan memperbaiki yang dapat digambarkan sebagai workshop. Selama workshop design RAD, pengguna merespons working prototype yang ada dan penganalisis memeperbaiki modul-modul yang dirancang (menggunakan perangkat lunak) berdasarkan respon pengguna.

\section{III.3. Fase Implementasi}

Penganalisis bekerja dengan para pengguna secara intens selama workshop untuk merancang aspek-aspek bisnins dan non-teknis dari perusahaan. Segera sesudah aspek-aspek ini disetujui dan sistemsistem dibangun dan disaring, sistem-sistem baru atau bagian dari sistem diuji coba dan diperkenalkan kepada stakeholder

\section{ANALISA DAN PERANCANGAN}

\subsection{Fase Perencanaan Syarat-syarat}

Dalam fase ini langkah-langkah yang dilakukan adalah sebagai berikut:

a. Gambaran umum dari trayek kerata api, yang bertujuan mengetahui data-data dari stasiunstasiun yang disinggahi dan dilewati oleh kereta api tayek Jakarta - Cirebon yang akan menjadi patokan dari aplikasi yang akan dibuat;

b. Mengidentitifikasi fitur-fitur berdasarkan tujuantujuan aplikasi atau sistem serta mengidentifikasi syarat-syarat informasi yang ditimbulkan dari tujuan-tujuan tersebut;

\subsection{Fase Workshop Design}

Setelah disusun sistem yang ada termasuk penyelesaian kendala-kendala atau permasalahanpermasalahan yang ada, tahap selanjutnya adalah mendesain aplikasi yang diusulkan agar dapat berjalan lebih baik dan diharapkan dapat mengatasi masalahmasalah yang ada.

Dalam fase ini peneliti membuat desain model aplikasi:

a. Perancangan spesifikasi proses yang dibutuhkan, dengan menerjemahkan proses-proses yang terjadi di dalam sistem ini kedalam bentuk algoritma sederhana yang akan di implementasikan dalam bentuk program;

b. Perancangan interface, dengan membuat rancangan layar tampilan yang berupa input-input yang bertujuan untuk memfasilitasi komunikasi antara pengguna dengan sistem. Setelah rancangan layar tampilan terbentuk maka dilakukan tahap implementasi;

\subsection{Perancangan User Interface}

Pada tahapan ini, peneliti merancang tampilan Antar Muka dari aplikasi.

a. Tampilan Menu Utama

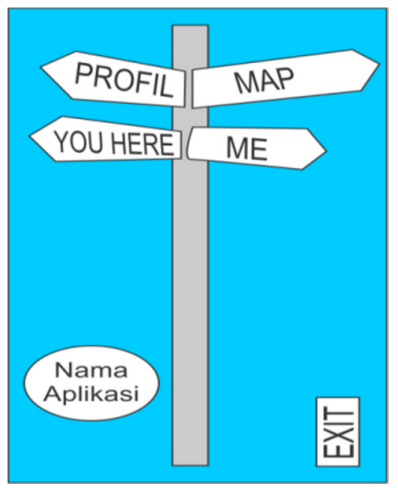

Gambar 2 Rancangan Menu Utama

Tampilan menu utama terdiri dari empat tombol menu utama yaitu Profil, You Here, Map, Me dan satu tombol Exit untuk keluar dari aplikasi

\section{b. Tampilan Menu Profil}

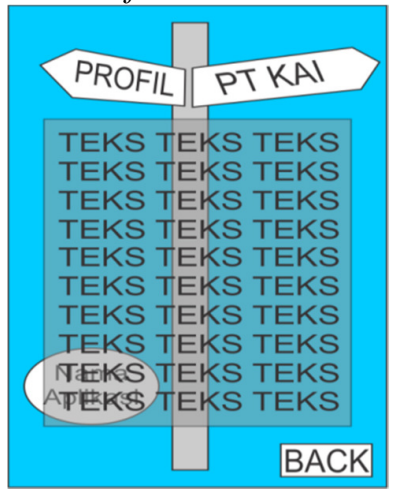

Gambar 3 Rancangan menu Profil 
Tampilan pada menu Profil ini menampilkan informasi tentang sejarah dari PT. KAI yang di ambil langsung dari situs resminya. Tujuannya memberikan informasi tentang sejarah dari moda transportasi kereta yang ada di Indonesia.

c. Tampilan Menu You Here

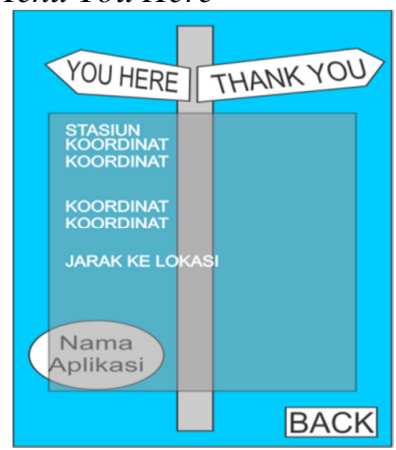

Gambar 4 Rancangan menu You Here

Tampilan pada menu You Here adalah koordinat dari stasiun terdekat dari posisi perangkat yang user gunakan dan posisi user itu sendiri serta jarak antara user dan stasiun terdekat.

\section{d. Tampilan Menu Map

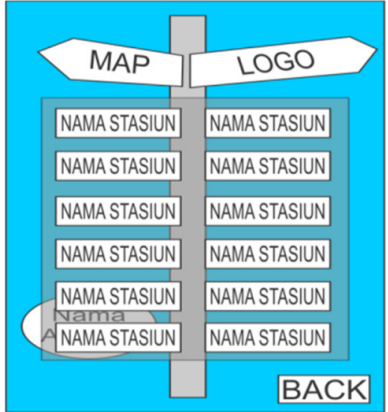

Gambar 5 Rancangan Menu Map

Tampilan pada menu Map adalah dua belas list nama staiun yang ada dalam aplikasi, yang ketika dipilih akan menampilkan posisi stasiun tersebut pada google map.

\section{e. Tampilan Menu Me}

Pada tampilan menu Me adalah profil pribadi dari pembuat aplikasi.

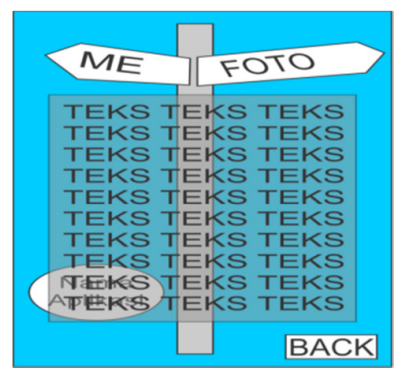

Gambar 6 Rancangan Menu Me

\subsection{Perancangan Use Case Diagram}

Use Case mendeskripsikan interaksi actor di dalam aplikasi yang di kembangkan. Dalam konteks ini peneliti memilih pengguna Android (user) sebagai actor.

Tabel 1 Identifikasi Actor dan Use Case

\begin{tabular}{|l|l|l|}
\hline No & Actor & \multicolumn{1}{c|}{ Description } \\
\hline 1 & User & $\begin{array}{l}\text { Orang yang mengakses data } \\
\text { dan mendapat notification } \\
\text { nama stasiun kereta yang } \\
\text { disinggahi melalui aplikasi } \\
\text { native yang terinstal pada } \\
\text { smartphone Android }\end{array}$ \\
\hline
\end{tabular}

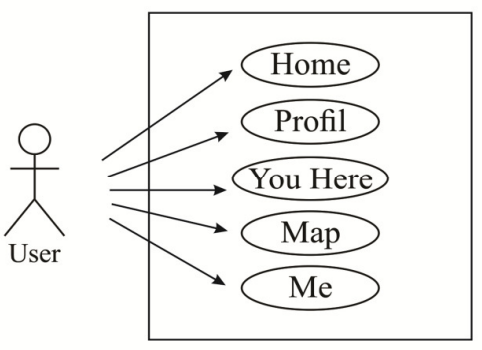

Gambar 7 Use Case Diagram

Dalam use case diagram diatas, user sebagai actor yang mempunyai use case pilih Profil, You Here, Map, Me.

\subsection{Perancangan Activity Diagram}

Activity Diagram menggambarkan katifitasaktifitas yang terjadi dalam aplikasi 'Stasiun Manakah?' dari aktifitas dimulai sampai aktifitas berhenti.

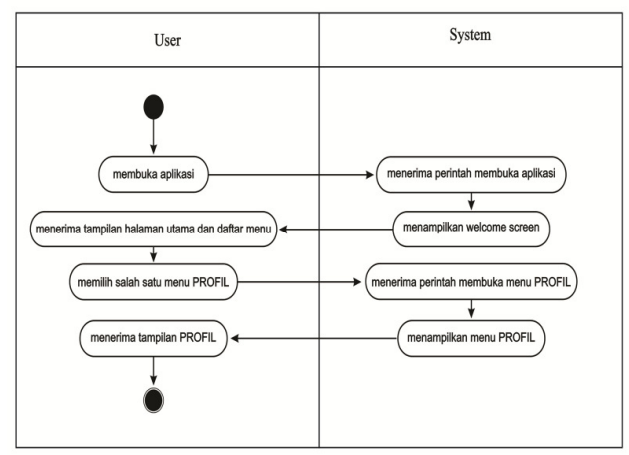

Gambar 8 Activity Diagram Pilih Profil

Di dalam Activity Diagram Use Case pilih profil, aktivitas pertama dimulai dari user dengan membuka aplikasi 'Stasiun Manakah?', lalu sistem merespon dan menampilkan menu Home yang berisi beberapa pilihan menu lain. Kemudian user memilih menu Profil, yang kemudian di respon oleh sistem dengan menampilkan profil KAI. 


\subsection{Fase Implementasi}

Implementasi merupakan tahapan presentasi dari hasil perancangan ke dalam program. Peneliti menggunakan Adobe Flash CS6 sebagai bahasa pemrograman yang di dalamnya sudah terdapat Android SDK (Software Development Kit). Dilanjutkan dengan pemasangan (install) ke smartphone Android serta melakukan pengujian atau testing aplikasi secara blackbox yaitu dengan mengetahui fungsi yang ditentukan dimana produk dirancang untuk melakukan sesuatu, pengujiannya dapat dilakukan untuk memperlihatkan bahwa masingmasing fungsi beroprasi sepenuhnya, pada waktu yang sama mencari kesalahan pada setiap fungsi (Pressman, 2002).

Setelah pengujian blackbox di lanjutkan tahap uji coba aplikasi dilapangan, tujuannya untuk mengukur akurasi dari koordinat yang sudah didapat dari google map dan untuk mengetahui apakah aplikasi yang sudah terinstal dapat berjalan sesuai dengan keinginan atau tidak.

\subsection{Pengujian Black Box}

Pengujian ini dilakukan dengan menguji validasi terhadap aplikasi 'Stasiun Manakah?'. Pengujian ini dilakukan dengan cara pengujian mandiri dengan menyebar beberapa kuesioner kepada masyarakat luar daerah Jakarta yang melakukan perjalanan pulang atau dari daerah berangkat ke Jakarta yang menggunakan smartphone Anroid.

Tabel 2 Pengujian Menu Home

\begin{tabular}{|l|l|}
\hline Kasus dan Hasil Uji \\
\hline Data Masukan & $\begin{array}{l}\text { User membuka aplikasi Stasiun } \\
\text { Manakah? Yang telah terinstal pada } \\
\text { smartphone Android. }\end{array}$ \\
\hline $\begin{array}{l}\text { Yang } \\
\text { Diharapkan }\end{array}$ & $\begin{array}{l}\text { Dapat menampilkan home screen } \\
\text { yang berupa tampilan button menu- } \\
\text { menu pilihan. }\end{array}$ \\
\hline Pengamatan & $\begin{array}{l}\text { Sistem dapat menampilkan empat } \\
\text { kategori button menu. }\end{array}$ \\
\hline Kesimpulan & Berhasil \\
\hline
\end{tabular}

\subsection{Pengujian Akurasi Koordinat}

Pengujian ini dilakukan untuk mengetahui seberapa akurat aplikasi 'Stasiun Manakah?' dapat membaca koordinat dari google map yang sudah dimasukan dalam sistem pengkodean. Tujuannya agar mengetahui apakah koordinat yang telah di ambil dari google map singkron dengan data yang ada di lapangan atau tidak.
Tabel 3 Hasil Pengujian 1

\begin{tabular}{|c|c|c|c|c|c|}
\hline Jakarta-Cirebon & Latitude & Longitude & Latitude & Longitude & Aplikasi berjalan (meter \\
\hline Jakarta (Kota) & -6.137293 & 106.814668 & -6.133887821 & 106.8220628 & 906. \\
\hline Bekasi & -6.23591 & 106.9985 & -6.240912346 & 107.0053291 & \\
\hline Cikarang & -6.270584 & 107.179991 & -6.270398469 & 107.1878168 & \\
\hline Karawang & -6.305876 & 107.300464 & -6.30932885 & 107.3053704 & 60 \\
\hline Cikampek & -6.406731 & 107.458768 & -6.408540028 & 107.4665874 & 893.443 \\
\hline \begin{tabular}{|l|} 
Pagaden \\
\end{tabular} & 6.453742 & 107.817061 & 6.459652108 & 107.8198961 & 729 \\
\hline Haurgeulis & -6.458572 & 107.940884 & -6.456402167 & 107.9490933 & 945.232 \\
\hline Trisi & -6.459977 & 108.161011 & & & \\
\hline Kedokan Gabus & -6.467752 & 108.106837 & -6.468823514 & 108.1153864 & 959 \\
\hline Jatibarang & -6.473021 & 108.306284 & -6.479839423 & 108.308502 & 798.1 \\
\hline Arjawinangun & -6.644682 & 108.41451 & -6.646899285 & 108.4217427 & 842.14 \\
\hline Cirebon & -6.705338 & 108.555296 & -6.709988995 & 108.5575752 & 576.5711 \\
\hline
\end{tabular}

\begin{tabular}{|c|c|c|c|c|c|}
\hline Cirebon-Jakarta & Latitude & Longitude & Latitude & Longitude & Aplikasi berjalan (meter) \\
\hline Jakarta (Kota) & -6.137293 & 106.814668 & -6.133887801 & 106.8220328 & 898.958182 \\
\hline Bekasi & -6.23591 & 106.9985 & -6.240922356 & 107.0054291 & 370.20 \\
\hline Cikarang & -6.270584 & 107.179991 & -6.271398469 & 107.1878388 & 873.091 \\
\hline Karawang & -6.305876 & 107.300464 & -6.30832885 & 107.3043704 & \\
\hline Cikampek & -6.406731 & 107.458768 & -6.408541028 & 107.4675874 & \\
\hline \begin{tabular}{|l|} 
Pagader \\
\end{tabular} & -0.453742 & 107.817061 & -0.453652108 & 107.8188901 & 203. \\
\hline Haurgeulis & -6.458572 & 107.940884 & -6.456302167 & 107.9470933 & 731.8176 \\
\hline Trisi & -6.459977 & 108.161011 & & & \\
\hline Kedokan Gabus & -6.467752 & 108.106837 & -6.468323515 & 108.1154864 & 958.8090 \\
\hline \begin{tabular}{|l|} 
Jatibarang \\
\end{tabular} & -6.473021 & 108.306284 & -6.474639424 & 108.3075021 & 224.9629 \\
\hline Arjawinangun & -6.644682 & 108.41451 & -6.647899285 & 108.4227417 & 978.0943 \\
\hline Cirebon & -6.705338 & 108.555296 & -6.709918995 & 108.5570752 & 546.5661. \\
\hline
\end{tabular}

Tabel 4 Hasil Pengujian 2

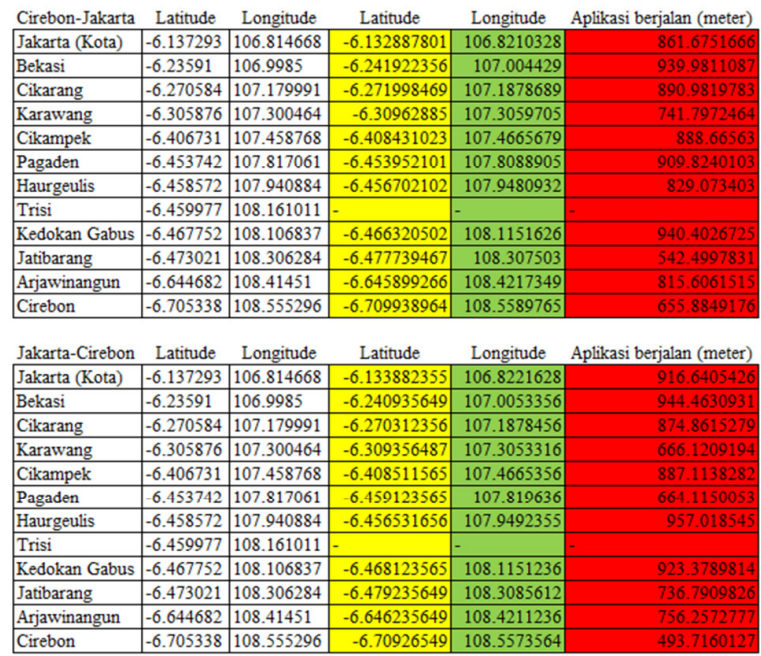

Tabel 5 Hasil Pengujian 3
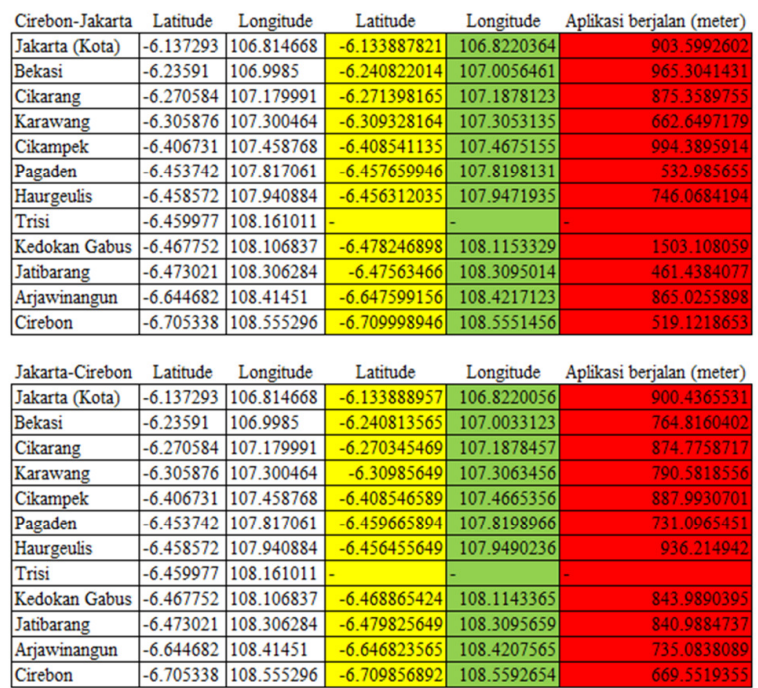


\section{KESIMPULAN DAN SARAN}

\subsection{Kesimpulan}

Dari pembahasan yang sudah diuraikan, dapat disimpulkan bahwa:

1. Aplikasi Android yang terkoneksi dengan GPS dapat membantu pengguna kereta mengetahui nama stasiun singgah yang dilewati.

2. Akurasi dari GPS smartphone Android dapat membaca koordinat yang telah di tentukan secara realtime tergantung dari spesifikasi smartphone yang digunakan.

\subsection{Saran}

Untuk pengembangan lebih lanjut, ada beberapa hal yang dapat peneliti sarankan untuk melengkapi aplikasi ini menjadi lebih baik lagi, antara lain:

1. Penambahan jadwal pemberangkatan dan kedatangan kereta api secara real time sehingga penumpang yang hendak melakukan perjalanan dapat memantau ketera api yang hendak ditumpanginya melalui smartphone yang dimiliki tanpa harus bertanya pada penjaga.

2. Penambahan jenis informasi suara yang lebih lengkap sehingga dapat memperjelas dan lebih menarik bagi user .

3. Penambahan database informasi nama stasiun singgah yang dapat mengcover sampai seluruh pulau jawa.

\section{Daftar Pustaka}

[1] A.A. Waskito (2009). Kamus Praktis Bahasa Indonesia.Jakarta : Wahyu Media.

[2] Arikunto, Suharsimi (2010). Prosedur Penelitian Suatu Pendekatan Praktek. Jakarta: Rineka Cipta.

[3] Anonymous. "Learning animal". From http://www.learnenglish.de/basics/animals.html, 30 Oktober 2013.

[4] Anonymous. "Action Script 3.0". From http://dasaranimasikita.blogspot.com/, $\quad 5$ November 2013.http://stackoverflow.com

[5] Chonoles, M.J, James A. Schardt. (2003). UML 2 for Dummies. New York: Willey Publishing, Inc.

[6] Di. H. Martinis Yamin, M.Pd, Dr. Jamilah Sabri, M.Pd. I (2010). Panduan Pendidikan Anank Usia Dini. Jakarta : Gaung Persada

[7] Kendall, Kenneth E dan Kendall, Julie E. (2008). Analisis dan Perancangan Sistem, Edisi Kelima (Versi Indonesia). Jakarta :Indeks.

[8] Mulyadi, Adi. (2010). Membangun Aplikasi Android. Yogyakarta : Multimedia Center Publishing.

[9] Nazir (1998). Metode Penelitian, Jakarta : Rineka Cipta

[10] Nugroho, Adi (2005). Rational Rose untuk Pemodelan Berorientasi Objek. Bandung : Informatika.

[11] Pressman, Roger S (2002). Rekayasa Perangkat Lunak. Yogyakarta : Penerbit Andi.

[12] Safaat, Nazruddin (2011). Pemrogaman Aplikasi Mobile Smartphone dan Tablet PC Berbasis Android. Bandung: Informatika.

[13] Septiawan ebta."KBBI Online". from http://kbbi.web.id/, 15 agustus 2013.

[14] Sugiyono (2010). Metode Penelitian Kuantitatif Kualitatif dan $R \& D$. Bandung : Alfabeta.

[15] Zaki, Ali. (2008). E-Life Style Memanfaatkan Beragam Perangkat Teknologi Digital. Jakarta : Salemba Infotek. 